\title{
A Study on Cultural Adaptation of Bangladeshi Male Students at UIA, Malaysia
}

\author{
Md. Akhtaruzzaman ${ }^{1, *}$, Monami Hoque ${ }^{2}$ \\ ${ }^{1}$ Department of Mechatronics Engineering, Kulliyyah of Engineering, International Islamic University Malaysia (IIUM), 53100 Kuala \\ Lumpur, Malaysia \\ ${ }^{2}$ Department of Human Science, Kulliyyah of Islamic Revealed Knowledge and Human Science, International Islamic University Malaysia \\ (IIUM), 53100 Kuala Lumpur, Malaysia
}

\begin{abstract}
This paper describes the extent to which Bangladeshi students at the University Islam Antarabangsa (UIA), Malaysia, experiencing a cultural gap while enrolling in the University. The main objective of the study is to examine the perceptions of Bangladeshi students on the cultural differences and its impact on their overall experiences while studying in UIA. The qualitative approach of phenomenology was employed in this study and the data were collected using in-depth and interactive interviews. The study has found that Bangladeshi students studying in UIA are experiencing a cultural gap, manifested in their homesickness, food problems, financial intricacy and language complexity. The uniqueness and significance of this study lies in the fact that it is an important and fundamental study about the cultural adaptation by Asian Muslim students in an Asian Muslim country.
\end{abstract}

Keywords Bangladeshi Students, Cultural Adaptation, Cultural Adjustment, Cultural Gap, Culture Shock, IIUM, UIA

\section{Introduction}

The well-rounded education in preparation for living and working successfully in the 21 st century needs not only to be higher but also deeper, broader and less nationalistic than that which has served past generations. More and more students arrive in foreign countries and follow studies at all levels, for various reasons. Like politics and economics, the educational sector is also influenced by the neoliberal belief that today's problems are best addressed by the market. It is often said that education must be made more efficient by being forced into the market model, moving away from the traditional concept of education as a publicly provided social goods. Malaysia has established an educational system, which is slightly different from those of western countries, on the basis of her own needs. In 1996 an educational reform bill was passed by the Malaysian parliament, to improve the quality of university-level education while widening its scope. It liberalized the higher-education system by allowing foreign universities to set up branch campuses in the country and allowing the Malaysian private sector to enter into the field. It also aimed to promote Malaysia as a regional centre for education by attracting foreign students.

* Corresponding author:

akhter900@yahoo.com (Md. Akhtaruzzaman)

Published online at http://journal.sapub.org/sociology

Copyright (C) 2011 Scientific \& Academic Publishing. All Rights Reserved
In 1986 there were less than 50 private institutions for higher education, but today this number has increased more than ten-fold to 539 (Badawi, 2006). One of the main objectives of the rapid growth of the private education sector is to allow local students to obtain high quality education in Malaysia without being burdened by the tremendous financial costs of pursuing equivalent courses abroad. The second objective is to attract more foreign students to pursue their tertiary education that contributes to strengthening the Malaysian economy as well.

UIA is a unique institution where thousands of students from hundreds of countries all over the world come to pursue their higher study. A significant number of these International students are from South Asian countries. It is assumed that many of these foreign students, who are coming from overseas in order to study in UIA, could be facing psychological problems which are related to the concept of cultural gap or shock. This paper interviews three Bangladeshi male students studying at University Islam Antrabangsa (UIA) Malaysia, also known as International Islamic University, Malaysia (IIUM), in order to find out how they are accommodating themselves in a new academic community. For the balanced multicultural society, the benefits of hosting students from diverse origins and the subsequent interactions should emphasize cultural understanding and synthesis based on trust and mutual appreciation of differences. Surviving in a multicultural world is a global challenge for intercultural cooperation and the responsibility of all communities involved in 
influencing the development of the peoples of the world[5].

\section{Preliminaries}

\subsection{Culture and Cultural Gap}

The common phenomenon that international students experience, while crossing the boundaries, can be identified as cultural gap. Different scholars see different connotations for culture and cultural gap. The British anthropologist Tyler wrote that culture is that complex whole which includes knowledge, belief, art, law, moral, custom, and any other capabilities and habits acquired by man as a member of society. American anthropologist Clyde Kluckhohn stated that, culture is a history-created system of survival types, dominant or recessive, having tendencies shared by the whole group or by some particular part in a certain period of time. Generally it is defined that culture is a form of life; the pillar of the power of thought; the scope includes rational knowledge; the main content as the form of what used to be the existence, the compulsory knowledge or insight, the conception of objects and the command of language. In its broad sense, culture refers to the sum of the material and spiritual wealth that has been created in the historical practice of human society. In its narrow sense, culture is the social ideology and its corresponding systems and organizations, including viewpoints and ideas of politics, law, ethics, arts, religions, science and compatible systems [6].

According to the Oxford English Dictionary, culture gap is a systematic difference between two cultures which hinders mutual understanding or relations. Such differences include the values, behavior, and customs of the respective cultures. According to Domingues (1970), Cultural gap or distance has been implicitly regarded as an important factor in adjustment to cultural change and also relates to social learning approaches to cross-cultural transitions[7].

\subsection{Culture Shock}

The term Culture Shock was coined in the academic literature by anthropologist Oberg (1960). He invented the expression in order to define the kind of uncertain and troubled feeling, which generally occurs when people are faced with organizing their daily life in a new cultural environment. Eventually culture shock means the general state in which the individual has to cope with the adjustment to a new environment[8]. According to Furnham and Bochner (1986) the term culture shock cannot be seen as a scientific expression but as a term used by laypersons to characterize the unpleasant experiences made in a new culture. In close connection with this expression Furnham and Bochner describe such terms as 'jetlag' and 'alienation' [8].

\subsection{Cross-cultural Adaptation}

Cross-cultural adaptation is a complex process in which a person becomes capable to interact effectively in a culture other than the one he or she was originally socialized in. In the cross-cultural adaptation, cultural novelty has played an important role for a long time. Research has indicated a negative influence of cultural novelty on adaptation outcomes[9]. Young defined cross-cultural adaptation is "as the entirety of the phenomenon of individuals who, on relocation to an unfamiliar socio-cultural environment, strive to establish and maintain a relatively stable, reciprocal, and functional relationship with the environment" [6].

\subsection{Socio- Cultural Adjustment}

Socio-cultural adaptation is best explained within a social skills or cultural learning paradigm. Several authors have identified different domains of socio-cultural adaptation; for example, Black and Stephens (1989), who have researched intercultural adjustment in the management field, specify the following three domains[3]:

- General adjustment (managing and performing daily life activity).

- Interaction adjustment (relating effectively to host nationals).

- Work adjustment (accomplishment of work-related objectives).

For overseas students, academic adjustment is clearly one of the main domains, although work adjustment may still occur if they have a part-time job. Their interactional adjustment also involves getting on well with other overseas students, from a range of countries[10].

\section{Methodology}

This paper uses the interview data to examine the relationship of multicultural experience in relation to their socio-cultural adaptation. Respondents were asked to provide the following background information: nationality, gender, age, length of stay at the university, pervious overseas experience, type of residence like university hall and general impression of the university. Then they were also asked some questions related to their study and some questions related to their part time jobs. The respondents were also asked to summarize their overall experience of working and studying together.

The interview questions were chosen to find out there strategy to balance their study and work environment in a foreign culture which is different from their own. For international students, academic adjustment is clearly one of the main domains, and also adjustment in workplace is important since they are supporting their tuition and living cost with their salaries. The questionnaires were semi-structured, so that all the issues can be covered and necessary information can be obtained from each of the interviews.

Three students were interviewed separately where they were asked the same questions and the speeches were 
audio-recorded which were used as transcribed. The questionnaire was divided into several categories like socio cultural adjustment, interactions and co-operations, study and work. Each interview was approximately 35 to 50 minutes long where the questions-answers and valuable opinions are expressed by the interviewers. Finally all the data collected from the interview were studied and scrutinized carefully to identify the difficulties, cultural differences, adjustments and overall experiences of the respondents to adapt with the new environment.

\section{Information about Respondents}

Three Bangladeshi male post graduate students of UIA (IIUM) were interviewed. The general information about these three students are as follows.

\subsection{Respondent 1}

- Age: 25

- Field of study: Masters in Qur'an and Sunnah at Kulliyyah of Islamic Revel Knowledge and Human Science (IRKHS), 2nd semester. He is also a Hafiz (1993) in the Holy Qur'an.

- Type of accommodation: Mahallah Al-Faruque (one of the male hostels in UIA).

- Type of works: He is working in two part time jobs. One is in Mahallah convenience shop and another one is in an International Madrasha (School). It is at Idaman, nearby UIA campus. There he teaches the students to memorize the Holy Qur'an.

\subsection{Respondent 2}

- Age: 28

- Field of study: Master of Science, Mechatronics Engineering, 3rd semester.

- Type of accommodation: Mahallah Siddique, (one of the male hostels in UIA).

- Type of works: He is appointed as a Tutor and Lab Demonstrator in the Kulliyyah of Engineering. His job is to teach about the assigned subjects and to evaluate class performances, quizzes, to assign projects and assignments. $\mathrm{He}$ is also working as a research assistant in the Engineering Department. Earlier, he worked as an employee at a Call Centre for one month.

\subsection{Respondent 3}

- Age: 29

- Field of study: PhD in Islamic Jurisprudence (Fiqh and Usul e Fiqh ), 1st Semester.

- Type of accommodation: Mahallah Siddique (one of the male hostels in UIA).

- Type of works: He is a Research assistant at UIA. He is also doing some other jobs independently like editing, typing, data collection from websites etc. As he is fluent in speaking
Arabic Language, sometimes he works as an Arabic Translator outside of the UIA campus.

\section{Scrutinizing the Interviews}

Knowing a new culture is difficult and it takes longer time to adjust. Wagner and Magistrale described this process as, "one step forward, two steps back" [13]. This section focuses on the comments that the interviewees made about their daily lives, social interaction, feelings about the multicultural classroom environment, experiences on doing part time jobs and about the balance between their work and study.

In Cairo, Egypt, Respondent 1 had one Malaysian roommate from whom he came to know about Malaysia and UIA. Some of Respondent 3's undergrad teacher's in Bangladesh are UIA alumni. He came to know about UIA and Kulliyyah of IRK from them. Respondent 2 also visited UIA to attend a conference, before he applied for his Master's here.

\subsection{Socio-cultural Adjustments}

\subsubsection{Daily Life Experiences}

At the first time, it was difficult for them to adjust due to communication media and culture differences. They had to communicate in English with others, which is not their mother tongue. Respondent 1 mentioned that his daily life in foreign country was not new. Previously he was in Cairo for four years regarding his Undergraduate studies. So he was experienced about the daily life in abroad. But he mentioned, 'Sometimes I feel that something is missing from my life. I miss my family members very much'. Respondent 3 is very satisfied with the living standard in UIA, Malaysia. He mentioned, 'Here I can access the wi-fi internet connection everywhere through which I can continue keep-in-touch with my family members'. This is the first time for Respondent 2 to stay outside of his home country even from his own family. But he was able to adjust himself with the new environment with his intellectuality and patient. He enjoys the different foods very much. According to his words, Sometimes I surprised and often cannot understand how quickly the time is flying in Malaysia. But in this busy time I miss my parents and my younger brother so much'.

\subsubsection{Social Interaction}

As Respondent 1 and Respondent 3 stay in Undergraduate Block, each of them has to share their rooms with other international students. In the Undergraduate Block, basically four students have to stay together in a large room having four compartments for each of them. Respondent 1 stays with other three Bangladeshi Post Graduate students while Respondent 3 has two local and one international students who are doing undergraduate at UIA. Respondent 1 has some international friends who also study in UIA and they are very 
friendly. Sometimes his friends give him lift with car from Mahallah (Hostel) to Kulliyyah (School) or from Pasar Malam (small evening market beside UIA campus). He is very happy with them.

Respondent 3 has to adjust with his roommates and according to his speech, his roommates are also very kind and helpful specially the local students. Respondent 2 has a separate room with a great privacy as he stays in Post Graduate (PG) Block. In front of his room he has three international students from Nigeria and Somalia. $\mathrm{He}$ sometimes shares his feelings and foods with them. He also helps them by editing some of their documents related to their research work. Sometimes he needs to speak very slowly with his friends to make them understand about his thought, but he is very happy and comfortable with them for their friendly behavior.

\subsubsection{Feelings about Local food}

They have some difficulties with the local foods because of being oily and very different from their country foods. But some of the Malaysian food items are enjoyable, according to Respondent 2. But he missed some Bangladeshi dishes like Pitha, which his mother used to make in different occasions. Respondent 1 said, 'In Cairo, I used to cook by myself. But here in hostel, I am not allowed to cook. I have to eat in canteen and adjust with local foods'.

Most of the foods in Malaysia are sweet but they do not have the special dishes called 'Sweets' which is the traditional food item in Bangladesh and India. Respondent 2 miss Sweets very much and sometimes he goes to Mashzid Zamek to buy Sweets from some Indian shops. Respondents are also like the Malaysian traditional fruits. They found some different fruits which are very sweet in test and very delicious. They also found that some of their traditional fruits are also available here like Mango, Banana, Guava, Jackfruit, Litchi, Pineapple, Watermelon etc. Various kinds of juices and drinks are also available here which are very much enjoyable to them.

\subsubsection{Local Climate}

The respondents said that in Bangladesh, they have six seasons. Here they found only the summer. The sun is too hot. They face the scorching heat and sweat a lot. Still Respondent 2 mentioned, 'Off course six seasons are pleasant. But during the climate change, some people face some minor health problems in my country. But it is easy to adjust in one climate. However, I miss winter and autumn and also miss our seasonal fruits'. He also said that though it is very hot here, it is pleasurable. All the offices, labs and even vehicles and public transportations have well air conditioning systems. There are a lot of green hills around UIA campus that make the scenery very cool and beautiful.

'The rain in Malaysia is very interesting but the monster thunderstorm makes me afraid sometimes', said Respondent 2.

4.1.5. Taking part in local and social events
Respondent 1 took part in one home stay program at 'Pahang' and Respondent 3 took part in two home stay programs, one is in 'Pahang' and another one is in 'Bukit Tingi'. Respondent 3 said that it was totally different experience for him. He mentioned, 'I never see any culture like this where a family accept an unknown foreign person not only as a part of their family members but also like their own child'. He stayed there for three days and took part in the local events like playing local games and attending cultural activities. According to Respondent 1, 'It was a very nice experience. They treated me as their own son'. He also participated at their local mosque as an 'Imam' since he is a Hafiz in Qur'an. Respondent 2 said that he went to 'Bukit Jalil' upon getting an invitation from a Malaysian friend. A kind of cultural competition was going on there and he enjoyed that event very much. He also participated on some University Educational Tour like "Parliament visit in Malaysia". He said, 'I never get a chance to visit our own Parliament in Bangladesh but here I got the opportunity which is very much appreciated'. Actually he expends much of his time at lab to do his research works and involves with a few outside activities.

\subsection{Adjustment with Academic Studies}

\subsubsection{Sharing Ideas in Class}

When the respondents were asked whether they can express their ideas clearly in class they replied that now they can express themselves clearly in class but they have to follow some different techniques. Respondent 3 said that in his Kulliyyah of Islamic Revel Knowledge (IRK), majority of the students and the teachers are from Arab countries. He can speak Arabic but he is not a native Arab speaker. So sometimes he feels shy to express himself in class. Respondent 2 said that he tries to express himself slowly so that everyone can understand. While teaching as a tutor or a lab demonstrator, Respondent 2 asks the students that is he clear to them or not.

Since Respondent 1 is in the Centre for Languages and Pre-University Academic Development (CELPAD), he said, 'Once in a week I have to participate in group discussions. Our teacher assigns a topic and we need to discuss about that'. Respondent 3 said that in IRK classes, there are a little scope to have group discussion in class. Though Respondent 2 passed the English Proficiency Test (EPT) at the first time, he replied that actually in Engineering, there is also a little scope for group discussion in class. The lecturer explains most of the topics in each class. But for any assignment or project, they make some groups having two or three members and continue the project together.

\subsubsection{Availability of Books and Journals In Library}

The respondents replied that UIA library is one of the famous libraries in Malaysia and rich in terms of resources. They have a modern system and their collections are very rich. However, they have one major complain which is, 
difficulty to get books that they require due to the less number of copies of that particular book. Respondent 2 said that he just try to borrow the necessary books in the beginning of the semester. If he misses, he tries to identify borrower of the books, and then he requests him or her to have the book for one or two days and then he makes photocopy of the required chapters. Though the library is rich in its numerous kinds of books, the students suggested that the library should increase the number of a particular book. Respondent 1 mentioned another important issue; there are some journals that students cannot borrow from library. He said, 'Last semester, I wanted a CD about a debate on Jesus Christ. The library authority told me that I can borrow the CD just for one hour. So it was quite difficult for me to watch the video in one hour as well as preparing the analysis for my project'.

\subsubsection{Comments on Teaching Methods}

The respondents commented that the teaching method is satisfactory. Most of the teachers are very helpful. They are very friendly and explain the subjects to make us clear. They have extra times for consultancy with the students. Respondent 3 stated that in UIA all the class rooms have the modern technologies like computer, projector and well sound systems. He also mentioned one of his personal experiences with his lecturer. According to him, 'Our teachers behave like a father or elder brother to us. One of my teachers, in my very first class, gave me RM 300 and said that it is a gift from your professor to you. He is from Arab country and very generous'.

However, the respondents stated that there are few teachers who are moody who say, 'You are a postgraduate student, you have to do by yourself, go to library, and search by yourself and try to identify the solution'. According to Respondent 1, 'If the teachers say like that, I will not be able to learn from them. The teachers say 'read'. But they should explain to me about the methods or techniques that I should follow to study'. Respondent 2 stated that in the Kulliyyah of Engineering, the electronics devices that they use inside the class rooms are very good in quality. But sometimes if some problem occurs with a particular device, it becomes difficult for them to understand the lecture. He recommended that the technicians and engineers should be aware of these issues.

\subsection{Adjustment in Workplace}

\subsubsection{Describing Work Environment}

Respondent 1: He works at an International Madrassa (International School) and in his Mahallah convenience shop. Regarding the work environment at Madrassa, Respondent 1 said that sometimes he faces problem because there are some students, who know neither English nor Arabic. So it is very difficult to communicate with them. According to Respondent 1, sometimes the Malaysian students come and talk with him in Malay which makes some interesting moments. The Malaysian students behave very well to him.

Respondent 2: He is doing his part time job as a tutor or a lab demonstrator in his own Kulliyyah. He has to work for nine hours per week. His job is to guide the students to do the lab experiments. He also has to evaluate class performance, quizzes, assignments and also some projects. $\mathrm{He}$ is also doing research work at lab. In some earlier time he was working in a call centre for one month, outside of the UIA campus, to support one of his friends. While describing about the environment in call centre, he said, there were four or five employees who tried to manage all the 24 hour schedules of a day to support the clients. The environment was fine there but while he had the schedule at night he faced a great problem to catch the next day's class. While talking about the environment inside the campus, about the lab and demonstration class, Respondent 2 said that the university environment is very much good and comfortable.

Respondent 3: He works with his teacher in his office room as a research assistant. According to him, 'It is actually a mini library. I can get most of the important data from his room'. He also added that his teacher provides him some fast foods and drinks like tea, coffee, juice etc. Respondent 3 also worked as an Arabic translator in one of the Malaysian Resort called Affa Mousa, one of the beautiful places he had ever seen. It was very interesting for him to do the job and he goes there during the vacation.

\subsubsection{Job Satisfaction}

Respondent 3 and Respondent 1 are satisfied with their part time jobs. Respondent 1 said, by doing part time at the convenience shop, gaining extra experiences like dealing with different types of customers, prices of different commodities etc. Respondent 3 said that now he is doing coursework. So he doesn't have enough time to do outside job. He says, 'My job inside UIA campus is very convenient for me. I can study in the library and also can perform my prayers at the central mosque. I am planning to do outside job after finishing my coursework'. Respondent 2 stated, 'Actually, this is not the main job for me. I want to finish my masters and then will go for Ph.D. Then I will apply to find my expected job that I am looking for'. This part time job is to support himself in Malaysia and he said that it is okay for this situation.

The respondents stated that though they have to work hard, they are satisfied with their salary since they can bear the living cost as well as their tuition fees of the semester. Since they want to become independent and reduce the financial burden of their family, they are doing these part time jobs.

\subsection{Balance between Work and Study}

These three students truly work hard to balance between their study and job. According to Respondent 1, I am working during weekends for my part time job. So it is not clashing with my class time. I manage my times for assignments at Tuesday and Thursdays and also in the 
morning for weekends'.

Respondent 2 said that actually it is difficult to make proper balance of time for study, research, class and do some other works together. What he does, he makes a schedule of his tasks and tries to finish his works based on the schedule time. But sometimes he feels very tired. He added, 'Two days ago, I did not sleep for two days since I had some tasks to finish and the following morning I had a class. So I attended to the class then took a lab demonstrator class and after that I went for prayer. After my prayer I felt that it is not possible for me to do anything if I do not take a sleep. So I went to my room and I slept for 4 or 5 hours and then felt fresh'. Respondent 2 also said that, most of the time he expends to work in the lab at midnight to finish his MSc. Research work. Midnight is very cool and he gets more concentration to do his research.

Respondent 3 said that at the beginning of the semester, he can allocate enough time for his job but at the middle or end of the semester, he needs to reduce his workload. He continued, 'Suppose I was spending four hours per day for my job but before my exam I spend one hour. When I reduce my work hour, off course it hampers my salary. That's why I have to work hard at the beginning of my semester'. Sometimes Respondent 3 also feels very tired in balancing work and study.

\section{Outcomes of the Study}

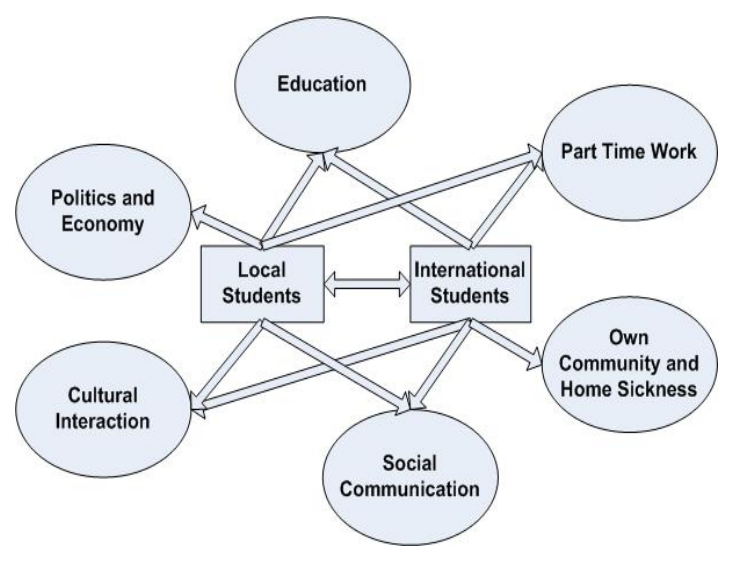

Figure 1. Basic relational diagram of cultural adaptation based on the interaction of the foreign and local students with social parameters

Some important social parameters are identified which are strictly related with the adaptation process of the students and the foreign socio cultural activities. Figure 1 shows a relational diagram between the students and the parameters while describing the direct connections and interactions to adapt with a new socio cultural environment. Education is the most vital parameter and also can be considered as a base to have an opportunity to stay with a foreign society. So, there are direct and strong connections between the students and education system. The students may or may not be involved in part time jobs depending on their dependency and financial support, so there is a moderate relationship. Cultural Interaction and Social Communication can be considered as another two parameters with which the local students are more familiar and have direct participations while the international students have some limited access to these parameters. There is no interaction for the overseas students with the local Politics and Economy where only local students are allowed. Similarly, individual community of the foreign students has no communication with local students while the international students have direct access and interactions to their own community. Between the local and international students, there exists a deep relation through which all the parameters can be identified to adapt with the foreign culture.

The study draws an example of cultural adjustment which is very important not only for the Bangladeshi students but also for all the overseas students to identify, help and guide them about the complex and dynamic process of the cross-cultural adaptation in foreign countries. The findings of the study are accentuated as,

- The daily life experience of the respondents is quite good here. They are adjusting with the new environment. They need to communicate in English with others, which are not their mother tongue, but still they are trying their best to understand others.

- While interacting with other nationalities, they face problems due to other's pronunciation and accent which is very different for them to understand, but still they have some international friends who are very helpful to them.

- The students are facing little difficulties in socio-cultural adjustment but the UIA environment is very satisfactory. They are very positive about getting introduced with people to take flavor of different cultures.

- Although the respondents were facing difficulties in adjusting with local foods and climate for the first time, but they are enjoying some of the local foods and also adapting with local climate.

- All the respondents took part in local social activities. This reflects their eagerness to be acquainted with the Malaysian culture and society.

- At the beginning the students faced some problems in understanding the class lectures properly. But they are overcoming this barrier by taking notes in class and consulting with lecturers to clarify their confusion. Most of the times, they are successful in expressing their ideas to the class.

- The students feel very comfortable in being grouped with other nationalities since they are eager to gain knowledge about other cultures. By interacting with the local and overseas students they are improving their English language efficiency.

- The Bangladeshi students are very satisfied with the teaching method of UIA.

- The Bangladeshi students are very pleased with their working environment. Their boss treats them very well and has a very cordial relationship. They face no difficulty in understanding instructions given at workplace and are interacting fruitfully with other nationalities at their workplace. 
- All the respondents are handling their part time jobs inside and outside of the campus successfully.

- The Bangladeshi students are satisfied with their jobs and gaining some extra experiences. They can bear their living cost as well as tuition fees with the money earned. They can live independently in a foreign country like Malaysia.

- All the respondents reported that sometimes they feel very tired in handling both study and work. At the same time, they become very upset; they miss their family and their country. However, these students are balancing their job and study effectively by maintaining a good socio cultural communication.

\section{Conclusions}

The Bangladeshi students are trying their best to communicate effectively with people from local and other cultures; they are motivated to communicate, gaining knowledge and skills to interact effectively with others. The students are putting their best effort and are ready to be familiar with the values, beliefs, behavior, as well as the environmental situation of Malaysian culture. The reason may be as like Neuliep (2003) [11], 'The Bangladeshi students also strongly believe that cultural differences can hinder people from understanding each other well. As a bridge between these different cultures, intercultural communication plays an important role to facilitate effective communication'. The students assume that with proper understanding of the host culture, they can adjust and adapt properly with foreign society, carry out their academic activities successfully and perform efficiently at their job. Hofstede and Pedersen argued that [12] 'culture is rather like the color of your eyes; you cannot change it or hide it, and although you cannot see it yourself, it is always visible to other people when you interact with them'.

\section{ACKNOWLEDGEMENTS}

Authors are very much thankful to their honorable parents and teachers. They also would like to express their gratitude to the Department of Mechatronics Engineering, Kulliyyah of Engineering and to the Department of Human Science, Kulliyyah of Islamic Revealed Knowledge and Human Science, International Islamic University Malaysia, 53100 Kuala Lumpur, Malaysia.

\section{REFERENCES}

[1] Al-Sharideh, K. A., \& Goe, W. R., 1998. Ethnic communities within the university: An Examination of Factors Influencing the Personal adjustment of international students. Research in
Higher Education, 39(6), 699-725

[2] Berger, C. R., \& diBattista, P., 1993. Communication Failure and Plan Adaptation: If at first you don't succeed, say it louder and slower. Communication Monographs, 60 (3), 220-238

[3] Black, J. S., \& Stephens, G.K., 1989. The influence of the spouse on American expatriate adjustment in Pacific Rim overseas assignments. Journal of Management, 1.15, 529-544

[4] Cai, D. A., \& Rodriguez, J. I., 1996. Adjusting to Cultural Differences: The International Adaptation Model. Intercultural Communication Studies, 6 (2)

[5] Hofstede, G., 1997. Cultures and Organisations: Software of the Mind, Intercultural Communication and its Importance for Survival. McGraw-Hill, London

[6] Young, Y. K. 2004. Long-term cross-cultural adaptation. In D. Landis, J. M. Bennett, \& M. J. Bennett (Eds.). Handbook of intercultural training. California: Sage Publications, 2004. 337-362

[7] Searle W., \& Ward, C., 1990. The Prediction of Psychological and Socio-cultural Adjustment During Cross-Cultural Transitions. International Journal of Intercultural Relations (IJIR), 14, 449-464

[8] Corsini, R. J., 1994. Encyclopedia of Psychology. Second Edition, Vol. 1. Wiley-Interscience

[9] Haslberger, A., 2005. Facets and Dimensions of Cross-cultural Adaptation: Refining the Tools. Personnel Review, 34(1), 85-109

[10] Spencer-Oatey, H., \& Xiong, Z., 2006. Chinese Students' Psychological and Sociocultural Adjustments to Britain: An Empirical Study. Language, Culture and Curriculum, 19(1), $37-53$

[11] Neuliep, J. W., 2003. Intercultural communication: a contextual approach. Boston: Houghton Mifflin Corporation

[12] Hofstede, G. J., Pedersen, P. B., \& Hofstede, G., 2002. Exploring culture: exercises, stories, and synthetic cultures. Nicholas Brealey Publishing August 2, 2002

[13] Wagner, K., \& Magistrale, T., 1997. Writing Across Culture: an introduction to study abroad and the writing process. NY: Peter Lang Publishing, Inc

[14] Hodge, S., 2000. Global smarts: the art of communicating and deal making anywhere in the world. New York: Wiley

[15] John, T. E. R., 1996. Handbook of Qualitative Research Methods for Psychology and the Social Sciences. Leicester: PBS Books. 203s

[16] Townsend, P., \& Wan, C., 2007. The impact of multicultural experience in the development of socio-cultural adaptation for international business students. International Journal of Educational Management. 21(3), 194-212

[17] Masud, M. H., Akhtaruzzaman, M., Bari, S. M. S. \& Anwar, F., 2011. Engineers' Obligations towards Sustainable Environment. In the proceedings of 2nd International Conference on Professional Ethics and Education in Engineering 2011 (ICEPEE '11). Kuala Lumpur, Malaysia, $85-92$ 
[18] Yusoff, Y. M., 2010. International Students' Adjustment in Higher Education: Relation Between Social Support, Self-Efficacy, and Socio-Cultural Adjustment. Australian Journal of Business and Management Research (AJBMR), No. 1, Vol. 1, 1-15

[19] Yusoff, Y. M., 2011. Self-Efficacy, Perceived Social Support, and Psychological Adjustment in International Undergraduate Students in a Public Higher Education Institution in Malaysia. Journal of Studies in International Education, June 16, 2011

[20] Leea, M. N. R., Muchtara, A., Sulehanb, J., Mastorc, K. A., Hungerd, A., \& Abdullaha, S., 2011. Contribution to the Understanding of Cultural Dynamics in Co-operation between Malaysia and Germany. Procedia - Social and Behavioral Sciences, Vol. 18, 2011, 204-212

[21] Ramalu, S. S., Rose, R. C., Uli, J., \& Samy, N. K., 2010. Personality and Cross-Cultural Adjustment among Expatriate Assignees in Malaysia. International Business Research, Vol. 3, No. 4, October 2010, 96-104

[22] YuSoff, M. S. B., Rahim, A. F. A., \& Yaacob, M. J., 2010. Prevalence and Sources of Stress among Universiti Sains Malaysia Medical Students. Malaysian Journal of Medical Sciences, Vol. 17, No. 1, 2010, 3-11

[23] Rahbar, E., \& Wahid, N. A., 2010. Ethno-Cultural Differences and Consumer Understanding of Eco-Labels: An Empirical Study in Malaysia. Journal of Sustainable Development, Vol. 3, No. 3. 255-262

[24] Crichton, J., \& Scarino, A., 2007. How are We to Understand the 'Intercultural Dimension'? An Examination of the Intercultural Dimension of Internationalisation in the Context of Higher Education in Australia. Australian Review of Applied Linguistics, Vol. 30, No. 1, 2007. Monash University Epress. 0.4.1-0.4.21

[25] Yusoff, Y. M., 2010. Demographic Differences among International Undergraduate Students at a Malaysian Public University. Global Journal of Management and Business Research, Vol. 10 Issue 2 (Ver 1.0), April 2010. 36-41

[26] Losin, E. A. R., Dapretto, M., \& Iacoboni, M., 2010. Culture and neuroscience: additive or synergistic? Social Cognitive and Affective Neuroscience Advance Access published January 18, 2010. 1-11

[27] Majid, S., \& Kassim, G. M., 2000. Information-Seeking Behaviour of International Islamic University Malaysia Law Faculty Members. Malaysian Journal of Library \& Information Science, Vol. 5, No. 2, December 2000. 1-17

[28] Rose, R. C., Ramalu, S. S., Uli, J., \& Kumar, N., 2010. Expatriate Performance in International Assignments: The Role of Cultural Intelligence as Dynamic Intercultural Competency. International Journal of Business and Management, Vol. 5, No. 8, August 2010. 76-85

[29] Marginson, S., \& Wende, M. V. D., 2007. Globalisation and
Higher Education. Organisation for Economic Co-operation and Development, EDU/WKP (2007). 1-84

[30] Alam, G. M., Rabby, T. G., Boon, T. L., Khan, I., \& Hoque, K. E., 2011. National development and student politics in Bangladesh. African Journal of Business Management Vol. 5(15), 6044-6057

[31] Sultana, N., 2007. National Identity, Mode of Networking and Integration of Bangladeshi Community in a Multi-cultural Society: Migrant Bangladeshis in Peninsular Malaysia. Akademika, 70. 77-101

[32] Thuraisingam, T., \& Singh, P. K. H., 2010. A Hermeneutic Phenomenological Approach to Socio-cultural and Academic Adjustment Experiences of International Students. The Journal of the South East Asia Research Centre for Communication and Humanities. Vol. 2, 2010. 91-113

[33] Pyvis, D., \& Chapman, A., 2007. Why university students choose an international education: A case study in Malaysia. International Journal of Educational Development Vol. 27, Issue 2, March 2007. 235-246

[34] Lim, T. O., Das, A., Rampal, S., Zaki, M., Sahabudin, R. M., Rohan, M. J., \& Isaacs, S., 2003. Cross-cultural adaptation and validation of the English version of the International Index of Erectile Function (IIEF) for use in Malaysia. International Journal of Impotence Research (2003) 15, 329-336

[35] Searle, W., \& Ward, C., 1990. The prediction of psychological and sociocultural adjustment during cross-cultural transitions. International Journal of Intercultural Relations. Vol. 14, Issue 4. 449-464

[36] Ward, C., \& Kennedy, A., 1993. Where's the "Culture" in Cross-Cultural Transition? Comparative Studies of Sojourner Adjustment. Journal of Cross-Cultural Psychology June 1993 vol. 24 no. $2221-249$

[37] Ward, C., \& Kennedy, A., 1993. Psychological and Socio-Cultural Adjustment During Cross-Cultural Transitions: A Comparison of Secondary Students Overseas and at Home. International Journal of Psychology, Vol. 28, Issue 2. 129-147

[38] Hofstede, G., 1986. Cultural differences in teaching and learning. International Journal of Intercultural Relations, Vol. 10 , Issue $3.301-320$

[39] Ang, S., Dyne, L. V., Koh, C., Ng, K. Y., Templer, K. J., Tay, C., \& Chandrasekar, N. A., 2007. Cultural Intelligence: Its Measurement and Effects on Cultural Judgment and Decision Making, Cultural Adaptation and Task Performance. Management and Organization Review, Vol. 3, Issue 3, 335-371

[40] Ward, C., \& Searle, W., 1991. The impact of value discrepancies and cultural identity on psychological and sociocultural adjustment of sojourners. International Journal of Intercultural Relations, Vol. 15, Issue 2. 209-224 